\title{
Recording 'Oral Histories' as a pedagogical tool in Media Studies: A Case Study
}

\author{
Archana R Singh 1
}

\begin{abstract}
This paper introduces 'Recording of Oral History' as a suitable pedagogical tool to inculcate the spirit of inclusiveness, respect for History, feeling of community, bridging knowledge gaps, understanding the importance of public opinion, understanding the meaning and nature of interpretation, respect for diverse perspectives besides learning the skill to conduct fruitful interviews. The pedagogy also sits well with the advances in the digital humanities in liberal arts. The students of 'Interpretative Reporting' Semester III of MA, Mass Communication and Journalism, School of Communication Studies, Panjab University, interviewed senior citizens to collect and record their memories of changing circumstances with time. The interviewees recounted their experiences - historical and personal - creating a veritable memory bank of, 'Then' and 'Now'. As unique as they are similar, their stories are oral histories that were recorded and presented using 'Guide to Transcribing and Summarizing Oral Histories of the Columbia River Highway Project' (Mershon, 2010). At the end of this exercise the effort to bridge the gap between the digital native students and digital immigrant adults around them is successful.
\end{abstract}

Keywords: Oral History, Media Studies, Public Opinion, Community.

\section{Introduction}

Journalism education is in a period of introspection with the educators striving hard to integrate the online and offline aspects of the pedagogies. Innovations and experimentation is the need of the hour because the hour long lecture' format may be ineffective for the digital natives. The high impact pedagogies across curricula call for more participatory hands on approach. Seminars, student projects, community involvement, collaborative research, and other such systematic, sustainable, and involving systems are being envisaged.

This paper introduces 'Recording of Oral History' as a suitable pedagogical tool to inculcate the spirit of inclusiveness, respect for History, feeling of community, bridging knowledge gaps, understanding the importance of public opinion, understanding the meaning and nature of interpretation, respect for diverse perspectives besides learning the skill to conduct fruitful interviews. The pedagogy also sits well with the advances in the digital humanities in liberal arts.

The project is for the journalism at the dawn of a new era in the construction and maintenance of a collective memory and shared history, along with aspirations for the future of journalism. It considers the new landscape of commemorative and interactive journalism facilitates storytelling to reach large global audiences simultaneously

1 Chair, School of Communication Studies, Panjab University, Chandigarh, India using new media; a growth area demanding the expertise of trained journalists while providing creative alternatives for journalism students.

\section{Methodology:}

The students of 'Interpretative Reporting' Semester III of MA, Mass Communication and Journalism, School of Communication Studies, Panjab University, interviewed senior citizens to collect and record their memories of changing circumstances with time. The interviewees recounted their experiences - historical and personal - creating a veritable memory bank of, 'Then' and 'Now'. As unique as they are similar, their stories are oral histories that were recorded and presented. Since oral history is the systematic collection of living people's testimony of their own experiences, the persons interviewed are not among those who actively participated in the Indian Independence movement, but those who struggled through the era. They have not contributed in the construction of their city but have helped mould it. Every little personal anecdote is part of the larger history. The project gave the students an opportunity to research about local senior citizens who are willing to share their lived experiences. Interviews were conducted at public parks of the Tricity: Chandigarh, Panchkula and Mohali, India. Rajanbir Singh Virk and Tushar Sharma both students of MA III Sem, assisted in collating data.

\section{Objective:}

The project is a result of a desire to bridge the gap between the digital native students and digital immigrant adults around them. Internet has 
advanced the quality of journalism (Shirky, 2008)through creation of pro-sumers who readily churn out content that could be a veritable sea of opinions floating in cyber space. Journalism students need to be trained to work across multiple platforms (Meyer, 2004) . The students need to be sensitive to needs of the society and be adept at using appropriate media. The skills in journalism would involve understanding the use of User Generated Content apart from reporting and writing. These skills are fundamental to the future of journalism (Mencher).

Recording oral history of seniors in Chandigarh:In 1952, a city was planned to not just serve as the capital of East Punjab but also to resettle thousands of refugees who had been uprooted during Partition. The location of the city site was a part of the erstwhile Ambala district as per the 1892-93 gazetteer of District Ambala. Subsequently, at the time of reorganization of the state on 01.11.1966 into Punjab, Haryana and Himachal Pradesh, the city assumed the unique distinction of being the capital city of both, Punjab and Haryana, while it itself was declared as a Union Territory and under the direct control of the Central Government. The city was named Chandigarh after the temple Chandi Mandir of Hindu goddess Chandi located near the site selected for the city (Chandigarh Administration).

Well conceptualized and systematically designed, the city attracted more than just the refugee population. Slowly turning into a melting pot of cultures, the city has attracted settlers from all over India. The demographic data indicate that between 1961 and 1971, the population increased by 144.59 percent, one of the highest for urban areas in India. According to 1981 census, it grew by another 75.55 percent, followed by 42.16 percent in 1991 and by 40.33 per cent in 2001 (with a total population of 9,00,635).

Since the population of Chandigarh comprises of first generation seniors who have settled here due to Partition, employment, initial businesses, or government jobs in the early years of the making of Chandigarh, they are also the first generation of individuals growing with the city.

This aging population of the city is a storehouse of memories. The memories that will form a part of the history of Chandigarh some day and will be invaluable over a period are today's anecdotes told to the younger generations, sometimes with a chuckle, a tear or a glint in the eye.

Central question: The central question was to learn about the perspectives of individuals who creators of this beautiful city are but will fall through the cracks because they were not 'important people'. The story of the common man never appears in any official document or data bank.

The generation of people interviewed for the project does not have access to digital record keeping tools that we have today. Our memories are thrown up by Facebook every day, but their memories are in their minds and have no way of being put on record if we do not talk to them. Without a record of this oral history, much of the personal history of the initial settlers of Chandigarh would be lost to future historians.

The factual history can be put together through documents, newspaper articles, speeches and other secondary data but the hopes, aspirations, family histories, fears, struggles of the ordinary people is lost forever as generations pass into next. History is not just the tale of the extraordinary but is a story of human experience.

\section{Discussion}

Whenever histories are interpreted through the reconstruction of the past, there is always a dilemma. Several historians create a narrative suitable to the contemporary political climate and own individual ideology. Lived experiences may have a personal viewpoint and memories tend to be recalled as series of instances interlinked through common sense or context. Yet, it is rare to get an opportunity to record the creation of the city through the eyes of its first dwellers. Some have trailed off to talk about Partition, some talked about their personal experiences, some described the growth of the city, while some spoke about whatever they wanted to, taking the interviewer with them on their journey into the past.

While recounting and recording these personal histories we need to realize that debates over the relationships between memory and history, and between individual and collective memory, often remain abstract and theoretical(Clark, 2002). Memory is memory for stories, and the major processes of memory are the creation, storage, and retrieval of stories (Schank, Roger C. \& Abelson, Robert P. , 1995).

There could always be a relationship between the 'beliefs' and the 'memories' of the respondents. Some memories are so deeply ingrained into the minds and overall frame of reference of an individual that it is impossible to differentiate the two. Beliefs are perhaps collective memories that have become a part of the folklore. The beliefs could be a part of an ideological stand-point; they could show up as attitudes and make themselves 
apparent as behavior. The fact that they continue to be interspersed in the memory bank cannot be denied and hence it is difficult to distinguish one from other.

Similarly, linguistic units could be also considered to be part of the memory bank because vocabulary, expression and turn of phrase is an outcome of education, training, practice, family background and class structure. Amongst the respondents some could be better equipped to verbalise their memories while others could be less articulate. Therefore, the narrative of the memory is not as important as the memory itself.

At some level the knowledge, comprehension and empathy level of the students also comes into play as they are sometimes unable to follow colloquial Punjabi terms and therefore fail to respond appropriately. The session then turns into 'then' and 'now' dialogue between the students and the respondents, who resemble their own grandparents.

Using Clarence Mershon's, 'Guide to transcribing oral histories' the narratives were recorded and transcribed. For the sake of clarity and convenience the discussion has been divided into broad headings.

Clothes: Senior citizens recollect the times when weddings were the biggest social occasion. Considerable amount of time was spent in getting the clothes stitched. Relatives would gather at the wedding home and work on stitching. Children used to wear their school dress for wedding functions. Astoundingly, Dhian Singh Sagi revisits his school days where he used to go in kurta-pyjama. Suram Singh, a 68-year-old ex-serviceman, recounts his mother stitching his kurta-pyjamas at home using Kapaas (cotton) cloth given its softness and sweatsoaking properties. At this point the interviewer/student hesitates at the word, 'kapaas' because it is the first time she has heard it and does not know the meaning. The seniors explain it to her and the conversation flows.

Education: Respondents reveal interesting insights into the education system of their era. All of them recognize the simplicity of life laying an impact on the education. There were fewer resources and distractions. Those who obtained education in rural areas reveal the scarcity of students in school. Teachers and parents both did not involve themselves into the child's development.
Parents were satisfied with their wards going to schools daily. Education was free for all in the villages and small towns. Vacations for students offered them a chance to visit their grandparents.

Those who received education in Chandigarh disclose that there was no competition amongst students and their parents. Not everybody wanted to be an engineer or doctor and only small number students used to opt for professional courses. The seniors have used the term 'doctor/engineer' as a metaphor for lucrative professional courses. It is in consonance with the preference given to these courses by youngsters in India.

Government had full control over the education. After 1956, when buildings started to come up, school was built with huge open grounds. Simple and spacious buildings were built for schools. There used to be an Education Inspector, who used to check the quality of education was maintained in schools. Takhti (slate) was an integral part of the school system. Students used to carry wooden slates to school and wash them after every use. Dr. Satish Kumar Sharma, 63-year-old retired Professor from Himachal Pradesh University, recollected his school memories of Government School, sector 14 wherein the teachers used to involve him in activities such as gardening given his physical strength.

Panjab University: Panjab University (PU) has been the alma mater to most of the respondents. PU was established in Lahore but post partition it was re-organized in Chandigarh once the city was planned and built. J.K. Nanda, 75-year-old retired advocate, vividly remembers the bus service for the students and staff during his university years from 1963 to 1965 as a student of Law. "The bus used to pass through Physics Department, Chemistry Department, and then take a turn at Guest House, the stop that exists even now", he is happy to recount about his journey in the bus. During his two-year course, the classes for the first year were held at Publication Bureau Building. During his second year, the three-year law programme was introduced and the department shifted to its current building. There was no Student Centre and the sports ground next to the administrative block was just an unkempt rocky area used for NCC. 
Manoj Kumar, who retired as Deputy Director (Academics) from Punjab School Education Board recalls that his sister got admission in Bachelors of Arts (English) course in Evening Studies Department but girls were not allowed in that department. His mother met Prof A.C. Joshi, the then Vice Chancellor and he considered the situation. He called up P.L. Anand, then Head of Department of Evening Studies, and asked him to enroll her in the department. She was the first lady student to be admitted in that department. Such instances highlight the passage of time and the changes that it brought about.

Ramesh Chand, Retired Head Chef of Panjab University Guest House recalls the days when the people used to look upon the university as heaven. Only a selective few faculty members used to commute in cars. Majority used to ride bicycles and there were cycle stands everywhere.

Lifestyle changes: Senior citizens loved to reflect on the lifestyle changes brought upon by the passage of time. One respondent described the incident when he was caught smoking by his father, who later did not talk to him for days. The issues of parental control and youth revolt are as old as the hills. Most stories revolved around this aspect.

Lack of technology had a severe impact on their physical activities. Women used to walk to riverbed to wash clothes using washing bats. Unlike the modern communication systems characterized by rapidity, wire service was the fastest means of communication. People used to wire messages through agents. Urgency had a lifetime of 12 hours back then.

The respondents recounted interesting social norms of the period. Leela Sharma, 77, useda 'kerosene-stove' after shifting to Chandigarh from Barnala in 1956, where they had used earthen stoves or Chulha. She revealed that us that the cook was expected to bather before entering the kitchen. It was a common practice in many households. She also wistfully regrets that young girls were not allowed to dring 'tea' due to fear of addiction. The gender disparity is clear from an early age given the fact that there was no such restriction for boys. Jaggery and Pakistani Salt were used in place of white sugar.
Reminiscing the era of long movie ticket queues, 79-year-old Gurdeep Singh Bedi fondly exclaims, "I still remember waiting in queus for four days every day before we finally got our ticket for Sholay!" His wife, Rajinder Bedi intervenes to take credit for getting those tickets on fourth day due to shorter ladies' queue. In another instance, for watching Amar Deep, a movie remembered by the couple for actor Rajesh Khanna's death, they had to stand in queue even before the intermission of the ongoing show. Movie-watching experience has undergone a change with the multiplex culture. Senior citizens gaze at the amount of food options in multiplexes given that only a selected few could afford to order samosas and cold drinks at the cinema hall in the olden times. Some recounted their love stories and some concentrated on the story of their struggle.

Changing city: They recall the broad roads and two wheelers, the trees that were being planted, making of the famous Sukhna Lake, the posters being displayed in neighbouring cities announcing the foundation stone laying of the first planned city of India. Many were impressed by the paved roads that were being constructed, many were glad that they had bought their houses at the time when government was inviting people to purchase land on the foothills of the Shivalik Range. Most residents of Chandigarh came from the Punjab province that included Punjab, Haryana and parts of Himachal Pradesh too. This accounts for the variety in the population of Chandigarh.

For the seniors the changes are far bigger than just the looks. The first generation sees it as a growth over time. They do not view the city as a static entity because they themselves are settlers. The later generations talk about increasing pollution, traffic, crime. The first generation looks at Chandigarh as that city which provides home and solace to any settler. They are able to empathise with the growing population of migrants to the city having been in the same predicament. Their memories do not really concentrate on the changing city but on how their own life had changed. Even when asked to comment about the city, they trailed into their own past and their efforts to settle here. 


\section{Conclusion}

These digital stories, if uploaded on a digital platform, promise to cross many borders and boundaries to engage and connect people in new and exciting ways, giving journalism a new lease of life in the digital era. The processes help students harness their journalistic skills of researching, interviewing, editing and broadcasting. At a social level, it connects young digital natives with senior citizens, some of whom are barely initiated to technology like smartphones. This project is a stepping-stone into the world of mass communication and community building at the local and global levels.

This project brought home to the students the power of the new digital media platforms in enhancing the research, background information, interviewing and finding the story angle for presenting journalism. This project also made the future journalists aware of the oral data available amongst the masses and its relevant usage. The fact that present day media is almost a social movement that does not believe in hierarchical structures but bends more towards participatory models (Castles, 2012), this exercise was the first tentative step in that direction. The wide chasm of the digital divide was apparent as a complex phenomenon with inherent inclusion and exclusion mechanisms. This project is an interaction between the senior citizens and the young aspiring journalists, some of whom have old grandparents at home. While some saw their grandparents in new light during the interview, others had never interacted with seniors at length. Some students narrated their experiences with tears in their eyes as they could imagine the horrors of partition of India and the effect that it had had on their families and fortune. Some interviews focused on their childhood experiences, early education, entertainment methods, popular trends, lifestyle and food. Each interview brought to light one area of experience and for the awe-struck technology savvy students the memories proved to be a learning experience. The students learned to create a hypothesis with a perspective, conduct background research, include the humanitarian angles, relating it to a worthy news peg and presenting it in an engrossing narrative without being overly sentimental.

Sample interview transcripts are attached as Annexures(I-IV).

\section{References}

Castles, M. (2012). What We Don't Know: Exploring the Inheritance of History through
Fiction.Thesis, University of Western Sydney, (D.C.A.).

Chandigarh Administration. (n.d.). Chandigarh : The city beautiful. Retrieved 2017 иил 1408 from Official website of Chandigarh Administration:

http://chandigarh.gov.in/knowchd_gen eral.htm

Clark, M. М. (2002 йил 01-11). Oral History Narrative and Memory Project: A first report. Journal of American History, 89(2), 569-579.

Mencher, M. (n.d.). News Reporting and Writing. Boston: McGraw Hill.

Meyer, P. (2004). The Vanishing Newspaper: Saving Journalism in the Information Age. University of Missouri Press.

Schank, Roger C. \& Abelson, Robert P. . (1995). Knowledge and Memory: The Real Story. In J. Robert S. Wyer, Knowledge and Memory: The Real Story (pp. 1-85). NJ: Hillsdale, NJ. Lawrence Erlbaum Associate.

Shirky. (2008). Here Comes Everybody: The Power of Organizing without Organizations. Penguin.

\section{Annexure I}

\section{Interview transcript I}

Interview transcript: Karam Prakash, 22, student of MA (J\&MC) at PU Chandigarh.

(Key KP- Karam Prakash-; MK- Manoj Kumar Sharma)

Manoj Kumar Sharma is an eminent educationalist from Mohali who runs educational institute providing primary and higher secondary education. Before he established this institution, he was Deputy Director (Academics) in Punjab Education Board. His simple personality, highly understanding nature, supportive willingness, dedication and excellent management are some of the virtues that he carries with him. In the interview he talks about the education system of Chandigarh during his time. (19601970)

KP: How was the education system in Chandigarh during your time?

MK: At that time, parents were not much aware. They had left it to the children. Interestingly, children, at that time, had a notion in mind that they have to study. Not like these days, there was almost no competition amongst students and parents. Not everybody wanted to be engineer or 
doctor. Only few aspired to be doctor or engineer and only small number students used to opt for professional courses. In Chandigarh, education was simple and free during our time. Government had full control over the education. People were dedicated, and teachers used to be very proud of being government teacher.

\section{KP: What was the quality and infrastructure of educational institutions?}

MK:In Chandigarh, right from the beginning, quality and infrastructure was very good. Though before 1956, schools were inside houses of people. There was school inside Panjab University's E block in Professor Colony. After 1956, when buildings started to come up, school was built with huge open grounds. Simple and spacious buildings were built for schools. Sectarian schools were among the first few schools in the Tri-city. Quality of the education was good in Chandigarh. Teachers were very dedicated. I remember my father was in state board and somebody brought sweets at home, but my father threw it in the streets. That was the character of the teachers at that time. You could not bribe them. Simplicity, dedication and honesty were evident attributes in teachers at that time. There used to Education Inspector who used to check the quality of education was maintained in schools. You will be shocked to see that matriculates of that time are well versed and have better writing skills then Masters of this decade.

\section{KP: How was teaching of students back then?}

MK: In early times, teachers were respected a lot by the students. Even though there was corporal punishment but still student's respect for teachers never faded away because students knew that teachers taught from the core of their heart. Our lack of respect towards teachers is not just morally wrong; it's sabotaging the education system. That's why it's time to really recognize the role teachers play in developing young people's minds and bettering society.

Now the scenario has completely changed. Back then, students were physically strong but mentally weak. But today tables have turned; students are mentally strong but physically weak. Hari Ram, then DAV College principal, was the strictest principal in Chandigarh. During examination, we didn't have any choices in questions like these days where you have multiple choice question answers, or you can attempt questions of your choice. So, it has changed the learning process. In our time, it was very difficult to get more than 60 percentiles.Earlier, fees were also very less because money requirements were also less. It was around 1 or 2 'anna' fees during our time.

\section{KP: How was your experience with takhti writing?}

MK: Young children, carrying takhtis under their armpits, has become a rare sight, however, the practice continues in rural areas, where a majority of students of public and private schools improve their writing on wooden slates with straw pens. He said though use of takhti was a bit difficult task for students as they had to bring the wooden slates to school and wash them after every use, yet their importance for academic development could not be denied. People, associated with calligraphy and fine art, are very critical of the declining trend of use of takhti and view it a threat to regional calligraphic art.

He believes takhti not only helps students develop good handwriting skills but also nourishes their calligraphic sense.

\section{KP: Tell me about your memories with Panjab University.}

MK:Panjab University was one of the renowned universities in India. After 1947 the university had no campus of its own for nearly a decade. The administrative office was in Solan and the teaching departments functioned from Hoshiarpur, Jalandhar, Delhi, and Amritsar. Vice Chancellors were strict in earlier times. Once my sister got admission in BA English in evening studies, but girls were not allowed in evening studies. We met A C Joshi, and he considered the situation. He called up PL Anand, then VC, and asked him to enroll her in evening studies. She was first female student to be admitted in evening.

\section{Annexure II}

\section{Interview transcript II}

Interview transcript:Ravinder Singh, 23, student of MA ( J\&MC) at PU Chandigarh.

(Key RS- Ravinder Singh; AS- Ajaib Singh)

Chandigarh, India's most prosperous and greenest city was born of dreams at the time of one of the country's worst nightmares.

\section{RS:How old were you when you moved to Chandigarh?}

AS: "I was four-years old when my family had to leave Mint Gumery now an administrative district in Pakistan."

Ajaib Singh an old man with wrinkled skin now resides in Dyalpur, a small village located along 
the Chandigarh- Ambalahighway. When Chandigarh started to expand, and this village started to seem like a part of Chandigarh.

RS:Please share your past experiences and childhood memories of his life.

AS: In 1953, I was in 8th standard and before going to school I had to carry kettle of tea for his father ploughing fields in farms.

That's his most vivid memory of his childhood.

RS: Is there any difference in farming that you notice?

AS: " Yes, obviously. Now a days as the population is increasing, the technology is also increasing rapidly for the growth of human development, but In 1955 there were no tractors, electric motors and other modern agricultural equipment, oxen driven ploughing was there. Ploughs were traditionally drawn by the working animals such as cattle,oxes, but these days ploughs are drawn by tractors. Electric motors and tube wells were used for irrigation purposes, water was drawn out of wells by animals. Animals like cow, buffalo, oxen etc were connected to wheel.

My father used to wake up early at 4 am and go to fields with oxen driven ploughs and used to come back at around 9 am in the morning, but now, most of the youngsters like you wake up around 8am.

With smile on his face he adds, "This is the major difference."

\section{Annexure III}

\section{Interview transcript III}

Interview transcript: Dhruvan Sharma, 22, student of MA (J\&MC) at PU Chandigarh.

\section{(Key DS- Dhruvan Sharma; RC- Ramesh Chand)}

Born in Kangra district in 1940, 77-year-old Ramesh Chand lost his Father when he was just 2 year old, leaving him, his Mother and two elder brothers exposed to the harsh realities of life. Hailing from a poor background and struggling to make both the ends meet, he left his hometown at the tender age of 10, to work as a servant in various cities like Gurdaspur, Amritsar and Jalandhar.

In September 1960, at the age of 20, he came to Chandigarh and started working as a cook at a sweet shop in the Panjab university market where rich people used to come and one such person got him a job in administration block as a daily wager at Rs 45 per month. Ramesh went on to spend the rest of his life in the University as he worked as an attendant for 21 years in Teacher's home, now known as Faculty House and then as head cook of university Guest House for 16 years before retiring in 2001. Now, Ramesh along with his wife, runs a Dhaba in the university market and feed the students who are away from home.

DS:Tell me about your experience in the early years.

RC: "This university is like a Mother to me. I came here as an illiterate boy and became a man. Now, my children are also here. I love this place and have learned everything here."

\section{DS:Are there any changes that you observe?}

RC: "A lot changes in 57 years and Panjab University is no different. It has undergone a drastic change and I have seen it all. Earlier, people used to work here with utmost pride and passion but that is no longer the case now. The University was very clean and green back then as compared to now. It was so beautiful that People used to call it Heaven. There were just a few universities at that time." He added "Earlier, just 5-6 professors had cars and people used to look at them with awe whenever they passed. Things were quite simple as everyone used to ride a Bicycle and there used to be a cycle stand everywhere. We used to go to sector-17 on foot as there were limited sources of transport."

Reminiscing about the old times, He said, "There used to be massive respect for Professors and students used to fear them. It is sad to see the current times where there is a lack of dialogue unlike before and incidents of violence also occur. Studies were the main focus during those days and the atmosphere was very calm and peaceful."

\section{DS: Any change in food habits of people?}

RC: "We used to cook on stove, eat in brass plates and water was kept in pots. Fast Food was not at all popular and people preferred to eat Indian food. Solar cooker and baked vegetables were also not there. The way of serving tea was also very different as tea, sugar, milk was separately in tea pot, sugar pot and milk pot respectively. People used to eat simple food."

The story of Ramesh Chand is yet another example of the fact that the bedrock of Human existence is his or her ability to cope with the inevitable process called 'change'. 


\section{Annexure IV}

\section{Interview transcript IV}

Interview transcript: Anshu Vaid, 22, student of MA (J\&MC) at PU Chandigarh.

(Key AV- Anshu Vaid; G- Gian)

This is the story of a person who has loved, struggled and survived. We all have stories to tell whether we whisper or yell. Everyone has gone through something that changed them. This is the story which needs to be told and shared. Moving around human relationships, this is the story of Mr. Gian who fell in love with a girl in 1946, almost lost her, faced the bullets during 1947 partition, came back to India and struggled hard to survive. This is their 'How we met' story comprising various elements.

It is an eighty years old love story, when India and Pakistan were fighting for their share. This is the story of Mr. Gian and Mrs. Raj. They are not only an ageing couple but are best friends to each other. They keep fighting but love each other. They argue but end up agreeing to each other's point of view. Here are excerpts of conversation with them.

\section{AV: Please share some of your memories associated with Pakistan.}

G: I was the resident of Jukali village, Gujranwala, Pakistan. My father was the only person in the village who could read and write well. So, he was the one who used to write government letters, filling up government forms for the village residents. Back then, there were no typing machines, therefore, the work was done manually. Altogether, we were six siblings. I had done my schooling from a government school till class four. I had learnt both English and Urdu languages during the school, but I can read English as well.

\section{AV: How did you fall in love with your better} half during the era of 1940s?

G: I met her at Gujranwala. She belonged to village Gojra, district Raipur. Since she was known to our family, she used to visit our place with her father who was an elite business man. Those meetings followed short conversations between us. Amidst all the talks and the time spent together, we fell in love with each other profoundly. But neither I had courage to express her nor to my father who was looking for a suitable match for me. At that time, I was 20 years old and she was near about16. Due to our cultural and family notions, I had assumed that it is not going to lead anywhere. After few months, I got engaged to another girl who was the resident of Gujranwala only.

AV: All this was happening during not so happening year 1947. How did you face the trials and tribulations associated with the partition?

G: My elder brother was married and was living with his wife in the village Shekhupuri. I along with my mother had gone to visit them. By each passing day, the communal tension between Hindu, Muslims and Sikh escalated. The entire political scene was a pile of mess. At that time, Master Tara Singh, a prominent Sikh political leader came into limelight, who led the movement of reorganization of Punjab for the welfare of both Hindu and Sikh communities as a solution to the communal tangle. It was only 6 days left for my marriage and India and Pakistan was on the verge of division. The never-ending riots made us worried. We kept hiding at our places as authorities had ordered curfew. We belonged to a Pandit family which made us their (muslims) clear target. Then, an announcement was made that India and Pakistan have separated so it meant the exchange of both population and property. I was not having in touch with my father and had no clue about him. While people were moving out, there was firing from all the sides. I was alone in the crowd looking for my mother, my brother and his wife but to no avail. I kept myself buried under the dead bodies for two consecutive days to escape from the bullets. The army personnel took me out and somehow 1 managed to find my mother as well. Till date, I have no clue about my siblings and my father. The thought of wellbeing of Raj kept making rounds in my mind but I realized that I had lost her again.

AV: Although you lost her, yet you got married to her. How did it progress?

G: The train took us to Dehradun via Amritsar. It was difficult to begin a new life in the absence of your loved ones. So, I started working as a vegetable seller and was earning to make our both ends meet. Time passed by and we completed the two years of our separation from our birth place and separation from Raj as well. One fine day, I saw a girl strolling around with her father in the same market where I used to sell vegetables. My happiness found no end. I couldn't believe that the girl I kept longing for was standing right in front of me. I finally, found Raj. Her father knew me well. Her family was also going through financial crisis. The situations went favorable and with mutual discussion of her parents, we were ready to tie the knot. In 1949, we got married in Dehradun. 


\section{AV: From Dehradun to Chandigarh, how did you get settle here?}

G: Some of our relatives who were successful in escaping were residing in Punjab. During the initial years of our marriage, we started living in Ludhiana and I started working in association with city jewelers. The term, Jewellery designing was not coined back then but I started working as a jewellery designer in 1950s. Since childhood, I was fond of paintings and craving out accessory designs which gave me huge appreciation. During 1950s, I was the only one who was into this profession of designing, therefore, all the jewelers from nearby cities and villages used to visit me. This is how, we managed to survive.

\section{$\mathrm{AV}$ : What is the current scenario?}

G: Today, we are blessed with six children. We did our best for their upbringing and education.
From last ten years, we are staying here in tricity with one of our sons. We have travelled to every nook and cranny of the country. Presently, she is unwell and going through the most difficult phase of her life. She can't speak, can't hear and can't move. I have observed the current face of relationships, which are more like an agreement, based on personal benefits.

In the era of broken marital relations and rising cases of divorce, our relationship never lost its steam, and this is what love is, growing together.

Interpretation (Based on Guide to Transcribing and Summarizing Oral Histories of the Columbis River Highway Project) (Mershon, 2010) 